\title{
Development and application of a respiratory device on blood pressure in adults with high blood pressure
}

\author{
KORNANONG YUENYONGCHAIWAT ${ }^{1, *}$, CHUSAK THANAWATTANO $^{2}$, \\ SASIPA BURANAPUNTALUG ${ }^{1}$, KHAJONSAK PONGPANIT $^{1}$, PATCHARIN SAENGKRUT $^{1}$
}

\author{
${ }^{1}$ Faculty of Allied Health Sciences, Department of Physiotherapy, Thammasat University, Pathum Thani, Thailand \\ ${ }^{2}$ Department of Biomedical Signal Processing Lab, National Electronics and Computer Technology Center (NECTEC), \\ Pathum Thani, Thailand \\ *Corresponding author: Kornaong Yuenyongchaiwat, PhD; Faculty of Allied Health Sciences, Department of Physiotherapy, Thammasat University, \\ Pathum Thani 12121, Thailand; Phone: +66 2986 9213; Fax: +66 2516 5379; E-mails: ykornano@tu.ac.th; plekornanong@gmail.com
}

(Received: April 7, 2018; Revised manuscript received: September 6, 2018; Accepted: May 27, 2018)

\begin{abstract}
Purpose: The purpose of this study is to develop a prototype of a novel respiratory device that we validated and assessed clinically and examined the effect of prototype of respiratory device on blood pressure (BP). Methods: Prototype of respiratory device (TU-Breath Training) was designed with pressure cuff and application software was created. The immediate effect of resisted breathing was determined in 20 adults with high BP (systolic $\mathrm{BP} \geq 130 \mathrm{mmHg}$ and diastolic $\mathrm{BP} \geq 90 \mathrm{mmHg}$ ). A crossover study was designed. A total of 20 eligible participants were asked to sit quietly for $10 \mathrm{~min}$. Heart rate (HR), $\mathrm{BP}$, and oxygen saturation $\left(\mathrm{SpO}_{2}\right)$ were measured and recorded. After the resting period, all participants were randomized and counterbalanced for undergoing the set of inspiratory muscle training by TU-Breath Training and control group. A set of respiratory training were composed of 10 times per set for three sets, while the control group was asked to sit for 10 min. Results: After inspiratory training, both the systolic and diastolic BP decreased significantly. Compared with control group, using TU-Breath Training decreased systolic BP $(-7.00 \pm$ $5.93 \mathrm{mmHg})$ and diastolic $\mathrm{BP}(-5.95 \pm 8.88 \mathrm{mmHg})$, but did not show differences in $\mathrm{HR}$ and $\mathrm{SpO}_{2}$. Conclusion: The study indicated that in high-BP participants, the prototype of respiratory device (TU-Breath Training) elicits decreased BP.
\end{abstract}

Keywords: respiratory training device, immediate effect, inspiratory muscle training, blood pressure, hypertension, respiratory muscle strength

\section{Introduction}

Non-communicable disease (NCD) is leading cardiovascular risk factors for coronary heart disease, cerebrovascular disease (e.g., stroke), and kidney disease [1-4]. High blood pressure (BP) is one of the components of NCD and also metabolic syndromes [5-8]. Treatment for high BP could be pharmacological and non-pharmacological treatments, such as aerobic exercise, breathing exercise, and lifestyle modification [9-15]. The respiratory training devices have been commonly reported to improve respiratory muscle and decreased BP. These efficiencies are also encouraging diaphragm and lungs expansion. However, the respiratory device usually consists of mouthpiece and therefore accessory muscles (e.g., sternocleidomastoid muscle) might be used. A specific training for the inspiratory muscle (i.e., diaphragm) should be focused. Thus, the study proposes to research the development and the efficacy of the respiratory training device on BP. Therefore, the study was aimed to develop a prototype of a novel respiratory device and the effect of respiratory device prototype on $\mathrm{BP}$ among participants with high BP.

\section{Material and Methods}

Two components of the study were designed, namely development of respiratory training device and study on participants.

This is an open-access article distributed under the terms of the Creative Commons Attribution-NonCommercial 4.0 International License, which permits unrestricted use, distribution, and reproduction in any medium for non-commercial purposes, provided the original author and source are credited, a link to the CC License is provided, and changes - if any - are indicated. 


\section{Developmental of respiratory training device (TU-Breath Training)}

The TU-Breath Training system is composed of three main parts including an air-resistive respiration training device, an electrocardiogram (ECG) monitoring device, and a smartphone with dedicated application installed (Fig. 1).

In the air-resistive training device, the air cuff is covered with a tailored fabric to fit normal size of adult waist. It can be filled with air using a manual air pump. The air cuff has an airway connection to the pressure sensor with a flexible rubber pipe reinforced with a cable tie to ensure that there is no air leakage at sensor side port. The pressure sensor is a monolithic silicon piezoresistive transducer with measurement range $0-50 \mathrm{kPa}$. It has maximum error limit at $\pm 1.25 \mathrm{kPa}$ throughout measurement range. The pressure sensor outputs voltage level with the sensitivity of $54 \mathrm{mV} / \mathrm{kPa}$. The microcontroller (MCU) reads the pressure value through an analog-to-digital (ADC) module with sampling rate of $10 \mathrm{~Hz}$. The MCU then sends formatted data to a smartphone through bluetooth communication. The ECG monitoring device is composed of an instrumentation amplifier, ECG electrodes, an MCU, and a bluetooth module. The very low voltage signal from ECG electrodes is differentially amplified by 200 times using the instrumentation amplifier, which is then fed into ADC of the MCU with sampling rate of $125 \mathrm{~Hz}$. With this sampling rate, the resolution of $\mathrm{RR}$ interval is $8 \mathrm{~ms}$. The MCU transmits ECG data to a smartphone through bluetooth module (Fig. 2).

The pressure value sent from training device is then processed in a smartphone. The air pressure signal is also used for the respiration rate calculation. The signal from ECG monitoring device is processed in a smartphone for the HR calculation. Furthermore, the application provides real-time ECG signal graphically.

\section{Study on participants with high BP}

The validation and accuracy were monitored in 30 healthy participants including males and females. The study revealed that the validity was observed in heartbeat, inspiratory and respiratory muscle strength from the TU-Breath Training in healthy adults [16]. After the prototype of respiratory device has been validated, the TU-Breath Training was examined in participants who had high BP. The aim of this study was to determine the immediate of efficacy of the TU-Breath Training on $\mathrm{BP}$ among adults with high BP.

\section{Participants and design}

A crossover study was designed. A total of 20 participants including both males and females aged over 20 years old with high BP were recruited. Those participants who had high $\mathrm{BP}$ [defined as systolic $\mathrm{BP}(\mathrm{SBP}) \geq 130 \mathrm{mmHg}$ and/or diastolic BP $(\mathrm{DBP}) \geq 90 \mathrm{mmHg}$ ] were enrolled in this study. The exclusion criteria were recently unstable angina, myocardial infarction within 1 month, resting heart rate $(\mathrm{HR})>120$ beats $/ \mathrm{min}$, or SBP $>180 \mathrm{mmHg}$ or $\mathrm{DBP}>100 \mathrm{mmHg}$, or pregnancy woman. The ethics and protocol were approved by the ethical committee of Thammasat University, Thailand.

\section{Measures and apparatus}

Participants were instructed for the maximal inspiratory pressure (MIP) using the TU-Breath Training. The MIP was defined as the pressure in which the participants perform inspiration in a deep and slow manner without using accessory muscle. The study divided into two groups (i.e., training and control groups) that were randomly assigned. According to the training group, all participants were asked to sit quietly for $10 \mathrm{~min}$ and then $\mathrm{BP}, \mathrm{HR}$, and oxygen saturation $\left(\mathrm{SpO}_{2}\right)$ were measured. Participants performed the respiratory muscle training using the TU-Breath Training for $10 \mathrm{~min}$. The respiratory resistance was set as $40 \%$ of MIP. Finally, these participants were measured $\mathrm{BP}, \mathrm{HR}$, and $\mathrm{SpO}_{2}$ after completion of $10 \mathrm{~min}$. One week later, the participants were invited

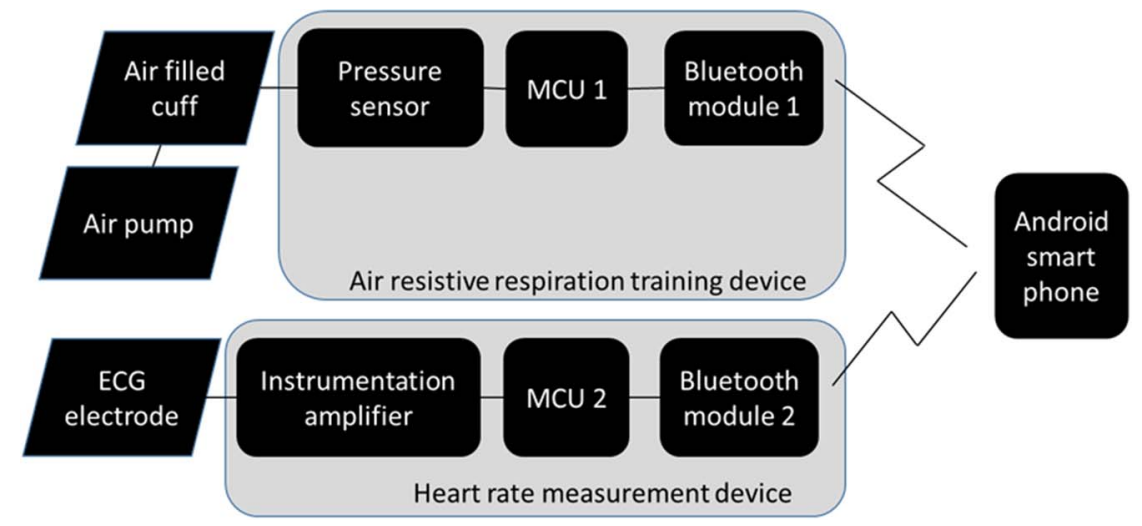

Fig. 1. Block diagram of the system 


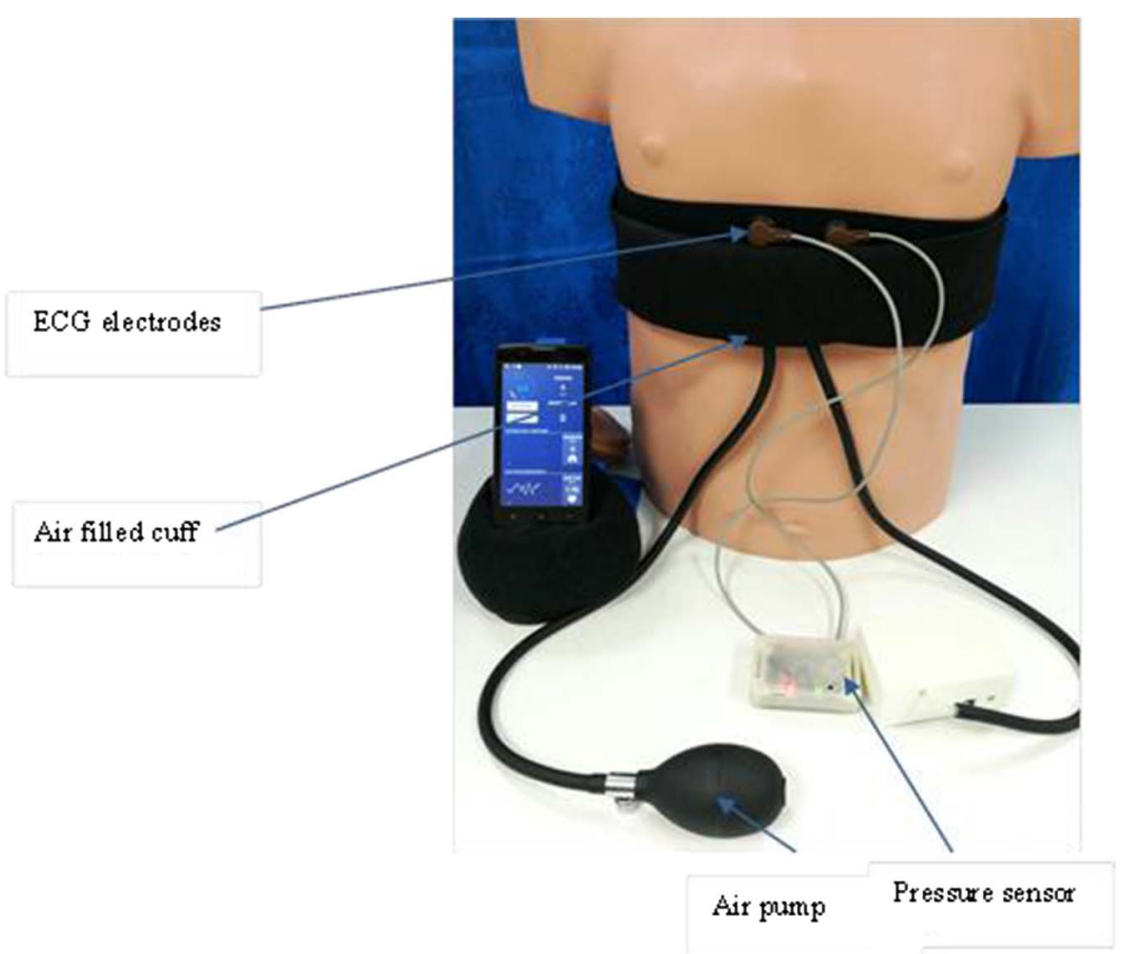

Fig. 2. Configuration of the respiration training system with the model

to return to the laboratory. $\mathrm{BP}, \mathrm{HR}$, and $\mathrm{SpO}_{2}$ were performed prior to and after the 10 -min resting, while the participants were asked to sit for $10 \mathrm{~min}$.

Resting BP (i.e., 10-min initial rest) was recorded on the left arm using a portable ECG monitor (Philips Intellivue MP20 bedside monitor, Phillips Electronics, Eindhoven, Netherlands), which had been calibrated. An appropriate arm cuff size was connected on the left semiflexed arm at the heart-level height as recommended by the manufacturer. In addition, two BP readings were taken at a 1-min interval, and a mean BP was calculated [17]. However, if the two $\mathrm{BP}$ readings differ by $>5 \mathrm{mmHg}$, a third $\mathrm{BP}$ reading was recorded and then the three $\mathrm{BP}$ readings were averaged. The $\mathrm{HR}$ and $\mathrm{SpO}_{2}$ were also performed using pulse oximeter from portable ECG monitor (Philips Intellivue MP20 bedside monitor). After 10 min rest, $\mathrm{HR}$ and $\mathrm{SpO}_{2}$ were recorded again at 11 th min. The average of two readings was noted.

\section{Results}

A crossover study design with a total of 20 participants was requested to perform respiratory muscle training with $40 \%$ of MIP for $10 \mathrm{~min}$. BP, $\mathrm{HR}$ and $\mathrm{SpO}_{2}$ were recorded before and after the study. There were no significant differences in an initial resting $\mathrm{BP}, \mathrm{HR}$, and $\mathrm{SpO}_{2}$ between training and control groups (Table I). Paired $t$-tests were then used to compare baseline values with training values, which indicated that resting SBP and
Table I Characteristic data of the participants

\begin{tabular}{lcc} 
& $n(\%)$ & Mean \pm SD \\
Gender & \\
$\quad$ Male & $10(50)$ & \\
Female & $10(50)$ & \\
Age (years) & & $58.25 \pm 13.78$ \\
SBP $(\mathrm{mmHg})$ & $139.15 \pm 15.82$ \\
$\mathrm{DBP}(\mathrm{mmHg})$ & $82.95 \pm 10.48$ \\
$\mathrm{HR}(\mathrm{bpm})$ & $80.50 \pm 15.59$ \\
$\mathrm{SpO}_{2}(\%)$ & $98.15 \pm 1.69$ \\
\hline
\end{tabular}

SD: standard deviation; SBP: systolic blood pressure; DBP: diastolic blood pressure; $\mathrm{SpO}_{2}$ : oxygen saturation; HR: heart rate

$\mathrm{DBP}[t(19)=5.280, p<0.001$ and $t(19)=2.998$, $p=0.007$, respectively $]$ had decreased significantly over training program, whereas resting $\mathrm{HR}$ and $\mathrm{SpO}_{2}$ had not changed significantly after training program (Table II).

In addition, a comparison between intervention and control groups revealed that training group had lower SBP and DBP $[t(19)=-4.395, p<0.001$ and $t(19)=-2.856$, $p=0.010$, respectively] than control group (Table III).

\section{Discussion}

This study aimed to develop the prototype of respiratory training (TU-Breath Training) and also determine 
Table II Comparison of the effect of pre- and post-training in 20 participants on SBP, DBP, HR, and $\mathrm{SpO}_{2}$

\begin{tabular}{|c|c|c|c|c|c|c|}
\hline & & $\begin{array}{l}\text { Pre-intervention } \\
\text { Mean } \pm \text { SD }\end{array}$ & $\begin{array}{l}\text { Post-intervention } \\
\text { Mean } \pm \text { SD }\end{array}$ & $95 \% \mathrm{CI}$ & $t(19)$ & $p$ value \\
\hline $\mathrm{SBP}(\mathrm{mmHg})$ & $\begin{array}{l}\text { TU-Breath Training } \\
\text { Control }\end{array}$ & $\begin{array}{l}139.15 \pm 15.82 \\
138.65 \pm 14.21\end{array}$ & $\begin{array}{l}132.15 \pm 18.24 \\
136.40 \pm 18.57\end{array}$ & $\begin{array}{r}{[4.23 \text { to } 3.19]} \\
{[-2.28 \text { to } 6.78]}\end{array}$ & $\begin{array}{l}5.280 \\
1.040\end{array}$ & $\begin{array}{r}<0.001 \\
0.312\end{array}$ \\
\hline $\mathrm{DBP}(\mathrm{mmHg})$ & $\begin{array}{l}\text { TU-Breath Training } \\
\text { Control }\end{array}$ & $\begin{array}{l}82.95 \pm 10.48 \\
83.60 \pm 9.21\end{array}$ & $\begin{array}{l}77.00 \pm 11.43 \\
81.85 \pm 12.68\end{array}$ & $\begin{array}{c}{[1.80 \text { to } 10.10]} \\
{[-1.69 \text { to } 5.19]}\end{array}$ & $\begin{array}{l}2.998 \\
1.064\end{array}$ & $\begin{array}{l}0.007 \\
0.301\end{array}$ \\
\hline $\mathrm{SpO}_{2}(\%)$ & $\begin{array}{l}\text { TU-Breath Training } \\
\text { Control }\end{array}$ & $\begin{array}{l}98.15 \pm 1.69 \\
98.25 \pm 1.52\end{array}$ & $\begin{array}{l}98.40 \pm 1.27 \\
97.90 \pm 1.21\end{array}$ & $\begin{array}{l}{[-1.16 \text { to }-0.58]} \\
{[-0.09 \text { to } 0.79]}\end{array}$ & $\begin{array}{r}-0.575 \\
1.677\end{array}$ & $\begin{array}{l}0.572 \\
0.110\end{array}$ \\
\hline HR (bpm) & $\begin{array}{l}\text { TU-Breath Training } \\
\text { Control }\end{array}$ & $\begin{array}{l}80.50 \pm 15.59 \\
78.35 \pm 15.60\end{array}$ & $\begin{array}{l}77.85 \pm 15.74 \\
77.95 \pm 15.88\end{array}$ & $\begin{array}{l}{[-0.75 \text { to } 6.05]} \\
{[-1.28 \text { to } 2.08]}\end{array}$ & $\begin{array}{l}1.040 \\
0.498\end{array}$ & $\begin{array}{l}0.119 \\
0.624\end{array}$ \\
\hline
\end{tabular}

SBP: systolic blood pressure; DBP: diastolic blood pressure; $\mathrm{SpO}_{2}$ : oxygen saturation; HR: heart rate; SD: standard deviation; CI: confidence interval; bpm: beats per minute

Table III Comparison of respiratory training (TU-Breath Training) and control groups on SBP, DBP, $\mathrm{SpO}_{2}$, and HR

\begin{tabular}{lcccrr} 
& TU-Breath Training & Control & $95 \%$ CI & $t(19)$ & $p$ value \\
$\Delta$ SBP $(\mathrm{mmHg})$ & $-7.00 \pm 5.93$ & $-0.40 \pm 3.59$ & {$[-9.74$ to -3.46$]$} & -4.395 & $<0.001$ \\
$\Delta \mathrm{DBP}(\mathrm{mmHg})$ & $-5.95 \pm 8.88$ & $-0.35 \pm 0.93$ & {$[-9.70$ to -1.50$]$} & -2.856 & 0.010 \\
$\Delta \mathrm{SpO}_{2}(\%)$ & $0.25 \pm 1.94$ & $-2.25 \pm 9.68$ & {$[-2.25$ to 7.25$]$} & 1.101 & 0.285 \\
$\Delta \mathrm{HR}(\mathrm{bpm})$ & $-2.65 \pm 7.26$ & $-1.75 \pm 7.35$ & {$[-4.99$ to 3.19$]$} & -0.460 & 0.651 \\
\hline
\end{tabular}

$\Delta$ : change; SBP: systolic blood pressure; DBP: diastolic blood pressure; $\mathrm{SpO}_{2}$ : oxygen saturation; HR: heart rate; CI: confidence interval; bpm: beats per minute

whether the prototype could be able to reduce BP in adults with high BP. The prototype was designed with pressure cuff for breathing and HR monitor. These monitors are displayed in smartphone. In addition, the prototype has been validated and the accuracy has been comparable with ECG monitor (Philips Intellivue MP20 bedside monitor) for heartbeat monitor and respiratory pressure meter $\left(\right.$ MicroRPM $^{\mathrm{TM}}$, Cat. No. RPM01, CareFusion Germany) for inspiratory muscle strength [16], respectively. The efficiency of the TU-Breath Training has been examined in participants with high BP and HR. The main findings of the study were that participants had shown decreased SBP and DBP $(-7.00 \pm 5.93$ and $-5.95 \pm 8.88 \mathrm{mmHg}$, respectively). Thus, the results confirm that the TU-Breath Training is effective in decreased BP after training for $10 \mathrm{~min}$.

Similarly, several studies have shown that acute effects of different inspiratory muscle-resistive loading on cardiovascular responses; it has been found that low intensities (i.e., 30\% of MIP during inspiratory-resistive loading) were associated with improvement in parasympathetic sinus node modulation and the influence of the respiratory sinus arrhythmia (RSA) [18]. In addition, HR and BP have been increased after $60 \%$ of MIP, which is of high intensities [19]. Furthermore, the systematic review with six studies demonstrated that effect of inspiratory muscle training at low intensities could promote an increase in HR variability (HRV) or reduction in sympathetic modulation in patient with hypertension [20]. Hence, this study evaluated the effect of TU-Breath Training with $40 \%$ of MIP in hypertensive participants and observed that BP decreased at $40 \%$ MIP. Therefore, these results by McConnell and Griffiths [19] and Archiza et al. [18] can be partially compared with this study. Increases in RSA might be resulting from increases in intrathoracic pressure and that improving baroreceptors or changes in the breathing pattern after resistive loading [21]. In addition, Seals et al. [22] acclaimed that negative intrathoracic pressure could increase lung volume during inspiratory phase and reduction in systematic arterial pressure. Therefore, these mechanisms that may, in part, explain the TU-Breath Training and decreased BP in hypertensive patients.

In addition, several studies have been reported that BP could be reduced by increased inspiratory muscle strength $[23,24]$. Ferreira et al. [24] examined the effect of inspiratory muscle training in patients with hypertension on BP and HRV over 8-week program. The study found that increased inspiratory muscle and reduced $\mathrm{BP}$ (i.e., SBP and DBP) were observed in the inspiratory muscle training. Improved cardiovascular autonomic control in adults with high BP was noted in the study, with increased parasympathetic nervous system and reduced sympathetic nervous system. Reductions of BP have been evidenced with the slow breathing and without load that might be from the RSA [25-27]. Decreased BP during respiratory training is related to improved baroreflex sensitivity, which decreases in 
sympathetic activity or increases in parasympathetic activity [25, 28, 29]. However, lack of baroreflex measurement or respiratory rate was not measured in this study. Therefore, the future study should be a consideration regarding baroreflex measurement, the respiratory rate control, and autonomic control (i.e., HRV).

The study is currently working on enhancing the accuracy and the performance of the respiratory training prototype. Furthermore, the study would further involve the efficacy of the respiratory training (TU-Breath Training), particularly reduced BP among participants with high BP. The study found that signals of the heartbeat, and respiratory and inspiratory muscle strength were accurate and validated. In addition, the initial investigation tested the acute effect of respiratory training prototype by decreased BP after 10-min training from over 20 participants who had high BP. Further trials are being planned whereby the study will determine whether using the prototype could improve the physiological and psychological parameters in participants with high BP. In addition, the ultimate version for the prototype is to provide a compact, portable, easy to use, cheap, and robust the combination of the physiological monitoring device (i.e., heartbeat, respiratory rate, inspiratory muscle pressure, and HRV). The cost of the device is also considered in the future study for the final developed version of the device.

\section{Conclusions}

TU-Breathing Training, which is a respiratory training exercise, might be an alternative device to control or reduce $\mathrm{BP}$ in participants with high $\mathrm{BP}$. However, a longterm study should be a consideration for improving autonomic control over cardiovascular system (i.e., BP and HRV) in hypertensive patients.

\section{***}

Funding sources: The study was fully supported by a research grant from the National Research Council of Thailand.

Authors' contribution: KY, CT, and SB designed the study. CT developed the respiratory device. KY, SB, KP, and PS collected the data. KY analyzed and wrote the original draft of the manuscript. All authors had approved the final version of the manuscript.

Conflict of interest: There is no conflict of interest in this study.

Acknowledgements: The authors would like to thank all the participants who participated in this study.

\section{References}

1. Jamalizadeh A, Kamiab Z, Nadimi AE, Nejadghaderi M, Saeidi A, Porkarami A: Prevalence of smoking and high blood pressure, two major risk factors for non-communicable diseases: The SuRF NCD (surveillance of risk factors of non-communicable disease) report 2012. J Cardiovasc Thorac Res 8, 183-187 (2016)

2. Mills KT, Bundy JD, Kelly TN, Reed JE, Kearney PM, Reynolds K, Chen J, He J: Global disparities of hypertension prevalence and control: A systematic analysis of population-based studies from 90 countries. Circulation 134, 441-450 (2016)

3. World Health Organization (2013): A Global Brief on Hypertension: Silent Killer, Global Public Health Crisis: World Health Day 2013. World Health Organization, Geneva

4. World Health Organization (2015): World Health Statistics 2015. World Health Organization, Geneva

5. Alberti G, Zimmet P, Shaw J: Metabolic syndrome - A new worldwide definition. A consensus statement from the International Diabetes Federation. Diabet Med 23, 469-480 (2006)

6. Grundy SM, Brewer HB, Cleeman JI, Smith SC, Lenfant C: Definition of metabolic syndrome report of the National Heart, Lung, and Blood Institute/American Heart Association conference on scientific issues related to definition. Circulation 109, 433-438 (2004)

7. Huang PL: A comprehensive definition for metabolic syndrome. Dis Model Mech 2, 231-237 (2009)

8. Yanai H, Tomono Y, Ito K, Furutani N, Yoshida H, Tada N: The underlying mechanisms for development of hypertension in the metabolic syndrome. Nutr J 7, 10 (2008)

9. Blumenthal J, Sherwood A, Smith PJ, Mabe S, Watkins L, Lin PH, Craighead LW, Babyak M, Tyson C, Young K, Ashworth M, Kraus W, Liao L, Hinderliter A: Lifestyle modification for resistant hypertension: The TRIUMPH randomized clinical trial. Am Heart J 170, 986-994 (2015)

10. Dimeo F, Pagonas N, Seibert F, Arndt R, Zidek W, Westhoff TH: Aerobic exercise reduces blood pressure in resistant hypertension. Hypertension 60, 653-658 (2012)

11. Gavish B: Device-guided breathing in the home setting: Technology, performance and clinical outcomes. Biol Psychol 84, 150-156 (2010)

12. Nicoll R: Hypertension and lifestyle modification: How useful are the guidelines? Br J Gen Pract 60, 879-880 (2010)

13. Schein MH, Gavish B, Baevsky T, Kaufman M, Levine S, Nessing A, Alter A: Treating hypertension in type II diabetic patients with device-guided breathing: A randomized controlled trial. J Hum Hypertens 23, 325-331 (2009)

14. Sharma M, Frishman WH, Gandhi K: RESPeRATE: Nonpharmacological treatment of hypertension. Cardiol Rev 19, 47-51 (2011)

15. Yuenyongchaiwat K, Pipatsitipong D, Sangprasert P: Increasing walking steps daily can reduce blood pressure and diabetes in overweight Thai participants. Diabetol Int 9, 75-79 (2018)

16. YuenyongchaiwatK, Buranapuntalug S, Pongpanit K, Thanawattano C: Accuracy and validity of heartbeat, respiratory and inspiration muscle strength parameters from a prototype of a respiratory device: Device-assisted deep and slow breathing, and inspiratory muscle strength in healthy adults. SMJ 32, 310-319 (2017)

17. Smith L: New AHA recommendations for blood pressure measurement. Am Fam Physician 72, 1391-1398 (2005)

18. Archiza B, Simões RP, Mendes RG, Fregonezi GAF, Catai AM, Borghi-Silva A: Acute effects of different inspiratory resistive loading on heart rate variability in healthy elderly patients. Braz J Phys Ther 17, 401-408 (2013)

19. McConnell AK, Griffiths LA: Acute cardiorespiratory responses to inspiratory pressure threshold loading. Med Sci Sports Exerc 42, 1696-1703 (2010)

20. de Abreu RM, Rehder-Santos P, Minatel V, dos Santos GL, Catai AM: Effects of inspiratory muscle training on cardiovascular autonomic control: A systematic review. Auton Neurosci 20, 29-35 (2017)

21. Calabrese P, Perrault H, Dinh TP, Eberhard A, Benchetrit G: Cardiorespiratory interactions during resistive load breathing. Am J Physiol Regul Integr Comp Physiol 27, R2208-R2213 (2000)

22. Seals DR, Suwarno O, Joyner MJ, Iber C, Copeland JG, Dempsey JA: Respiratory modulation of muscle sympathetic 
nerve activity in intact and lung denervated humans. Circ Res 72, 440-454 (1993)

23. Delucia CM, De Asis RM, Bailey EF: Daily inspiratory muscle training lowers blood pressure and vascular resistance in healthy men and women. Exp Physiol 24 (2017)

24. Ferreira JB, Plentz RDM, Stein C, Casali KR, Arean R, Lago PD: Inspiratory muscle training reduces blood pressure and sympathetic activity in hypertensive patients: A randomized controlled trial. Int J Cardiol 166, 61-67 (2013)

25. Joseph CN, Porta C, Casucci G, Casiraghi N, Maffeis M, Rossi M, Bernardi L: Slow breathing improves arterial baroreflex sensitivity and decreases blood pressure in essential hypertension. Hypertension 46, 714-718 (2005)

26. Mourya M, Mahajan AS, Singh NP, Jain AK: Effect of slow- and fast-breathing exercises on autonomic functions in patients with essential hypertension. J Altern Complement Med 1, 711-717 (2009)

27. Schein $\mathrm{MH}$, Gavish B, Herz M, Rosner-Kahana D, Naveh $\mathrm{P}$, Knishkowy B, Zlotnikov E, Ben-Zvi N, Melmed RN: Treating hypertension with a device that slows and regularises breathing: A randomised, double-blind controlled study. J Hum Hypertens 15, 271-278 (2001)

28. Bernardi L, Porta C, Spicuzza L, Bellwon J, Spadacini G, Frey AW, Yeung LY, Sanderson JE, Pedretti R, Tramarin R: Slow breathing increases arterial baroreflex sensitivity in patients with chronic heart failure. Circulation 105, 143-145 (2002)

29. Pinheiro $\mathrm{CH}$, Medeiros RA, Pinheiro DG, Marinho Mde J: Spontaneous respiratory modulation improves cardiovascular control in essential hypertension. Arq Bras Cardiol 88, 651-659 (2007) 